\title{
Foot pad health, plumage condition, integument and claw length of Lohmann Silver laying hens kept in small aviary housing systems, furnished cages and an aviary housing system
}

\begin{abstract}
In the 3rd, 6th, 9th and 12th laying month, foot pad health, plumage condition, integument and claw length were evaluated in 432 Lohmann Silver laying hens kept in three different housing systems: a small aviary housing system (Eurovent 625a-EU, EV) with different perch levels, a furnished cage system (Aviplus, AP) and an aviary (Voliere Natura, AV). Foot health was scored for hyperkeratosis and lesions on a scale from 1 (normal) to 5 or 4 (severe). Plumage condition was assessed with scores from 1 (worst) to 4 (best) for different body regions. Integument was assessed for lesions and claw length of the middle toe was measured. Mild foot pad hyperkeratosis was the most frequent finding in hens of all housing systems. Sole pad hyperkeratosis was less frequent in AP and occurred more often in EV and AV. Significantly more often hyperkeratosis in the region between toe and claw was observed in AP. Toe pad lesions and lesions between toe and claw were scored lowest in AV and highest in AP. An aggravation of plumage in the course of the laying period was observed in all hens. Hens showed a significantly better total plumage condition in AP compared to EV. Within housing system, group size had a significant influence on plumage condition. Plumage was better in smaller groups. Lesions of the integument were rarely detected. Claws were significantly shortest in AP, longer in AV and longest in EV. Perch design in EV was not significant for all traits except for comp lesions.
\end{abstract}

Key Words: Small aviary housing systems, furnished cages, aviary, foot pad health, plumage

\section{Zusammenfassung}

Titel der Arbeit: Fußballengesundheit, Gefiederstatus, Integument und Krallenlänge von Lohmann Silver Legehennen in Kleinvolieren, ausgestalteten Käfigen und einer Volierenhaltung

Im 3., 6., 9. und 12. Legemonat wurden Fußballengesundheit, Gefiederstatus, Integument und Krallenlänge von 432 Lohmann Silver Legehennen aus Kleinvolieren (Eurovent 625a-EU, EV) mit Sitzstangen in verschiedenen Ebenen, ausgestalteten Käfigen (Aviplus, AP) und einem Volierenhaltungssystem (Voliere Natura, AV) untersucht. An den Fußballen wurden Hyperkeratosen und Epithelläsionen anhand einer Skala von 1 (keine Hyperkeratose/ intaktes Epithel) bis 5 bzw. 4 (höchstgradige Hyperkeratose/ großflächige, tiefgreifende Läsion und hochgradige Ballenverdickung) beurteilt. Der Gefiederstatus einzelner Körperregionen wurde mittels einer Skala von 1 (gravierende Schäden) bis 4 (sehr gut) erfasst. Das Integument wurde hinsichtlich Läsionen untersucht. Die Ermittlung der Krallenlänge erfolgte mittels Messung der Mittelzehenkralle. Geringgradige Hyperkeratosen der Fußballen traten in allen Haltungssystemen am häufigsten auf. Hyperkeratosen des Sohlenballens kamen im Vergleich zu Hennen aus AP häufiger bei Tieren aus EV und AV vor. Dagegen war in AP ein häufigeres Auftreten von Hyperkeratosen im Übergangsbereich von Zehe zu Kralle zu beobachten. Zehenläsionen waren in AV am geringsten, in AP am stärksten ausgeprägt. Im Verlauf der Legeperiode wurde in allen Haltungssystemen eine Verschlechterung des Gefiederstatus beobachtet. Hennen aus AP zeigten insgesamt eine bessere Befiederung als Tiere in EV. Die Gruppengröße stellte sich innerhalb der Systeme als signifikant dar. Kleinere Gruppen zeigten einen besseren Gefiederstatus. Verletzungen des Integuments wurden selten festgestellt. Die Krallen waren in AP signifikant am kürzesten, gefolgt von AV und EV, wobei Hennen in EV deutlich längere Krallen aufwiesen als in den anderen Systemen. Die Sitzstangenposition in EV war für alle Merkmale mit Ausnahme von Läsionen des Kammes nicht signifikant. 
1.

Introduction

Small group housing systems and small aviary housing systems should replace furnished cages after 2011 in Germany. These systems should offer laying hens more space and enriched environmental conditions than conventional or furnished cages. New housing systems should be developed in respect to both, animal welfare and high hygienic egg production standards. Foot health, plumage condition, integument status and claw length are important indicators to evaluate housing systems for aspects of animal health and welfare. The objective of the present study was to evaluate if these welfare parameters can be improved in the newly developed small aviary housing system with different perch levels (Eurovent 625a-EU, EV). Housing systems compared with the small aviary housing system were a furnished cage system (Aviplus, AP) and an aviary housing system (Voliere Natura, AV) under the same management and feeding conditions. An important factor influencing the development of foot pad alterations is the housing system (TAUSON and ABRAHAMSSON, 1994; KEUTGEN et al., 1999; WEITZENBÜRGER et al., 2005). Findings in foot pad alterations range from mild hyperkeratotic alterations to inflamed ulcers of the foot, known as bumble foot (WANG et al., 1998). ABRAHAMSSON and TAUSON (1993) described hyperkeratosis as a main alteration in conventional and furnished cages. The frequent finding of hyperkeratotic alterations in cage-kept laying hens is seen to be caused by the pressure load on the foot while perching or standing on the wire floor (SIEGWART, 1991; KEUTGEN et al., 1999; WEITZENBÜRGER et al., 2005). Investigations of furnished cages and small group housing systems with 40 or 60 hens per compartment revealed mild hyperkeratosis of sole and toe pad in $57.4 \%$ of hens examined and more severe alterations with frequencies of $5.9 \%$ (severe hyperkeratosis and/ or deep epithelial lesions and/ or mild swelling of foot pads). In $1.9 \%$ of the hens, very severe hyperkeratosis and/ or deep and large epithelial lesions with moderate/ severe swelling of foot pads were observed. In addition, the brown layer line Lohmann Brown was significantly more severely and more often affected by hyperkeratotic foot pad alterations than Lohmann Selected Leghorn laying hens, while Lohmann Selected Leghorn layers were more frequently affected by epithelial lesions than Lohmann Brown hens (WEITZENBÜRGER et al., 2005). Epithelial lesions, mainly of the sole pad, are often observed in layers kept in free range, on floor or in aviary systems. This is explained by the contact to litter, excrements and the use of perches (KEUTGEN et al., 1999; WANG et al., 1998).

Poor plumage condition in laying hens can be caused by infectious diseases, ectoparasites, alimentary deficiencies and feather pecking. Acquired defects of plumage are also seen to be effected by housing system. APPLEBY et al. (2002) observed more feather damage in cages with a high stocking density and found a better plumage condition when troughs were elevated or a dust bath installed.

Lesions of the integument are related to housing system as well. The regions comb and cloaca are often affected by pecking wounds. KEUTGEN et al. (1999) observed more pecking marks on the cloacal region in floor housed hens and in free range than in cages. ELSON and CROXALL (2006) saw an increased number of comb wounds in alternative housing systems as a possible indication of more aggressive pecking. Claws of laying hens are characterised by a constant growth. Pawing as a natural behavioural pattern leads to abrasion and prevents an overgrowth of the claws. Hens in alternative housing systems show shorter claws than cage-kept hens (BARNETT et al., 
1997). Shortening devices in furnished cages were satisfactory for preventing a claw overgrowth (VITS et al., 2005). Long claws can lead to a higher risk of breakage or injury, caused by getting caught in the wire floor. KEUTGEN et al. (1999) found more broken claws in conventional cage-kept hens compared to alternative housing systems.

2. Material and methods

$2.1 \quad$ Housing systems and management

The three different housing systems included in this study were a small aviary housing system Eurovent 625a-EU (EV), a furnished cage system Aviplus (AP) and an aviary system Voliere Natura (AV) (supplied by Big Dutchman, Vechta, Germany). All housing systems were installed in one building and hens were kept under identical management conditions. Total number of hens housed in EV and AP were 1500 per system. Compartments of the small aviary housing system were built for group sizes of 40 or 60 laying hens, while in AP hens were kept in groups of 10, 20 and 30 hens per compartment. EV and AP were installed with three tiers and had a sloping wire floor. They were equipped with perches, nest boxes, dust bath and abrasion devices for the claws (adhesive stripes) below the feed trough. Floor space per hen was $750 \mathrm{~cm}^{2}$. White plastic perches (oval profile with a flat up- and under site, a polished surface with riffles on the front- and backside) were installed on an even level $(90 \mathrm{~mm})$ parallel to the front of the cage. In EV, plastic perches were combined with round metal perches $(\varnothing 35 \mathrm{~mm}$ ) in different levels. Compartments with the back perches elevated were equipped with usual plastic perches and heightened round metal perches (200 mm distance to cage floor). In compartments with a 'stepped' perch design, only metal perches were installed in a height of 200 and $275 \mathrm{~mm}$. The supply pipe for the dust bath filling was also useable for perching (Ø $45 \mathrm{~mm}$ ). Its surface and the metal perches were covered with galvanized zinc. For each hen, $15 \mathrm{~cm}$ perch-length was offered. Dust bath in AP was temporarily accessible for the hens and closed with a grating. In EV the dust bath was equipped with a mat, similar to the nest boxes, which was accessible throughout the day. Substrate for dust bathing in AP and EV (wood shavings, Ø 2-3 mm) was offered automatically once a day. Total number of hens housed in the aviary was 2500 . They were separated in two large groups of 1250 hens. AV had a central tier block with three tiers, equipped with a plastic slatted floor. Beside the tier block, a litter area (wood shavings) and family nest boxes were included. A wooden perch (55 x $55 \mathrm{~mm}$ ) in front of the second tier and round metallic perches above the third tier were installed. Furthermore, layers had access to a canopied outdoor area, littered with sand, wood shavings and straw. Litter was changed if needed. Laying hens kept in the trial from September 2005 to October 2006 were Lohmann Silver (LS). Layers were reared on the floor until an age of 18 weeks. Ad libitum feeding was automatically provided three times a day and water was supplied ad libitum. The light period took 14 hours.

Evaluation criteria

Foot pad health

Foot pad health was examined in a total number of 432 hens. Examinations took place in the 3rd, 6th, 9th and 12th laying month and 104 hens were tested in each month, with exception of the last (120 hens). Layers were randomly chosen of the three different housing systems with respect to group size and perch positions in EV. 
Alterations of foot pads were classified according to severity on a scale from 1 (no hyperkeratosis) to 5 (very severe hyperkeratosis) and from 1 (no lesion, no swelling of foot pad) to 4 (deep and large epithelial lesion and high grade swelling of foot pad) (Tab. 1). Both feet of the hen were examined and severity rating was assigned according to the most distinctive alteration. To evaluate whether different regions of the foot are differently affected by hyperkeratosis and lesions, we distinguished the areas sole pad, toe pad and the region between toe and claw.

Table 1

Classification of macroscopic findings in foot pads (Klassifizierung der makroskopischen Fußballen-Befunde)

\begin{tabular}{lll}
\hline Severity rating & $\begin{array}{l}\text { Macroscopic findings of } \\
\text { hyperkeratosis }\end{array}$ & $\begin{array}{l}\text { Macroscopic findings of } \\
\text { lesions }\end{array}$ \\
\hline 1 & no hyperkeratosis & $\begin{array}{l}\text { intact epithelium, } \\
\text { no swelling of foot pad } \\
\text { superficial lesion of the epithelium, } \\
\text { no swelling of foot pads }\end{array}$ \\
3 & mild hyperkeratosis & $\begin{array}{l}\text { deep epithelial lesions and/or } \\
\text { swelling of foot pad } \\
\text { deep and large epithelial lesions, }\end{array}$ \\
& moderate hyperkeratosis & high-graded swelling of foot pad \\
& severe hyperkeratosis & -
\end{tabular}

\section{$2.3 \quad$ Plumage condition}

The body regions head, neck, breast, belly, back, wings and tail were assessed separately using a scoring scheme from 1 to 4 . Score 1 meant high graded damage of plumage and bare regions, score 2 an explicit damage of feathers and/or bare areas, score 3 completely or nearly complete feathered, but damaged feathers, and score 4 was given for a very good plumage condition with nearly no feathers damaged. Points given for the different body regions were accumulated to a total sum so that the highest score for total plumage condition was 28 and the lowest 7.

\section{$2.4 \quad$ Integument and claw length}

Lesions of the integument were examined for comb, wattle, cloaca and legs using scores from 0 to $2(0=$ no lesion, $1=$ one lesion or few small lesions (up to $10 \mathrm{~mm}), 2=$ multiple small lesions or large lesions $(>10 \mathrm{~mm})$ ). Claw length of the middle claw was measured. A scoring scheme for claw length from 4 to 1 was used ( $4=20 \mathrm{~mm}$; 3 = 20-30 mm; 2 = 30-40 mm; 1 = > $40 \mathrm{~mm}$ ).

\section{$2.5 \quad$ Statistical analysis}

Statistical analyses of the status of foot pad health, plumage condition, integument and claw length were performed using the MIXED procedure of SAS, version 9.1.3. (Statistical Analysis System Institute Inc., Cary, NC, USA 2006). The fixed effects of housing system, group size, laying month and perch position were included in the statistical analysis. In addition, the interaction between housing system and laying month was regarded. Each compartment of the EV and AV housing systems was treated as a randomly distributed effect. Body weight of the hen within laying month was used as a linear covariate. Correlations between the residuals of foot pad health traits were calculated using the SAS procedure CORR. 


$$
\begin{aligned}
& \mathrm{Y}_{\mathrm{ijklmno}}=\mu+\mathrm{SYS}_{\mathrm{i}}+\mathrm{GR}(\mathrm{SYS})_{\mathrm{ij}}+\mathrm{MON}_{\mathrm{k}}+\mathrm{PER}(\mathrm{SYS})_{\mathrm{il}}+\mathrm{SYS}^{*} \mathrm{MON}_{\mathrm{ik}}+\mathrm{bx} \\
& \left.\mathrm{BW}(\mathrm{MON})_{\mathrm{km}}+\operatorname{comp}_{(\mathrm{SYS})}\right)_{\mathrm{in}}+\mathrm{e}_{\mathrm{ijklmno}}
\end{aligned}
$$

$\mathrm{Y}_{\mathrm{ijklmno}}$ : $\quad$ score for macroscopically determined alterations of sole pad, toe pad and the region between toe and claw; score for plumage condition; score for integument, score for claw length

$\mu:$ model constant

SYS : fixed effect of housing system ( $i=1-3)$

GR(SYS $)_{\mathrm{ij}}$ : $\quad$ fixed effect of group size $(\mathrm{j}=1-6)$

$\mathrm{MON}_{\mathrm{k}}$ : fixed effect of laying month $(\mathrm{k}=1-4)$

PER(SYS $)_{\mathrm{il}}: \quad$ fixed effect of perch position $(\mathrm{l}=1-4)$

SYS* MON $_{\mathrm{ik}}$ : interaction between housing system and laying month

$\mathrm{BW}(\mathrm{MON})_{\mathrm{km}}$ : body weight

comp(SYS $)_{\text {in }}$ : random effect of compartment of housing system $(n=70)$

b: linear regression coefficient

$\mathrm{e}_{\mathrm{ijk} \mathrm{klmn} \text { : }}$ random error

\section{Results}

Foot pad health was significantly influenced by housing system except the traits sole pad lesions and hyperkeratosis of the toe pad. Body weight of the hen showed a significant influence on the occurrence of toe pad lesions. The interaction between housing system and laying month was significant for foot health traits except sole pad lesions (Tab. 2). In all 432 hens examined, mild hyperkeratosis (degree 2) was the most frequently observed finding, followed by moderate hyperkeratosis (degree 3 ) and few cases of severe (degree 4) and very severe (degree 5) hyperkeratotic alterations. In EV in $9 \%$ of the layers moderate hyperkeratosis of the sole pad was observed, while in AP $4.9 \%$ and in AV $4.2 \%$ of the hens showed moderate hyperkeratosis (degree 3 ). In $1.4 \%$ of the layers kept in the EV, severe sole pad hyperkeratosis occurred. Toe pad hyperkeratosis was more severe in AP compared to the other systems. Moderate hyperkeratosis of toe pads occurred in $13.2 \%$ of AP hens. Within the region between toe and claw, we also found the most distinct alterations in the furnished cage system; $23.6 \%$ moderate hyperkeratosis, $6.9 \%$ severe and $4.2 \%$ very severe hyperkeratosis. For sole pad an intact epithelium (degree 1) was the most frequently observed finding in all housing systems, whereas hens in AV showed the highest frequency of intact sole pads (81.3\%). In $70.1 \%$ of laying hens in AP and in $60.4 \%$ of layers kept in EV, superficial lesions (degree 2) of the toe pad were found. An obviously smaller percentage (22.2\%) of hens in the aviary showed such alterations. Similarly, lesions between toe and claw were most frequent and severe in AP and scored lowest in AV (Tab. 3).

Body weight of the hen had a significant influence on the occurrence of toe pad lesions in the 3rd laying month with heavier hens being more affected. 
Table 2

Analyses of variance for different traits of foot pad health (Varianzanalyse für die Merkmale des Fußballenstatus)

\begin{tabular}{|c|c|c|c|c|}
\hline \multirow{2}{*}{$\begin{array}{l}\text { Effect } \\
\text { Trait }\end{array}$} & F-value & $\mathrm{P}$ & F-value & $\mathrm{P}$ \\
\hline & \multicolumn{2}{|c|}{ Hyperkeratosis sole pad } & \multicolumn{2}{|c|}{ Lesions sole pad } \\
\hline SYS & 8.67 & $<0.001$ & 1.43 & 0.241 \\
\hline GR(SYS) & 0.01 & 0.999 & 1.03 & 0.379 \\
\hline PER(SYS) & 1.44 & 0.231 & 1.02 & 0.314 \\
\hline MON & 1.19 & 0.313 & 0.20 & 0.896 \\
\hline SYS*MON & 3.45 & 0.003 & 1.25 & 0.281 \\
\hline \multirow[t]{2}{*}{$\mathrm{BW}(\mathrm{MON})$} & 0.88 & 0.477 & 1.06 & 0.374 \\
\hline & \multicolumn{2}{|c|}{ Hyperkeratosis toe pad } & \multicolumn{2}{|c|}{ Lesions toe pad } \\
\hline SYS & 1.69 & 0.186 & 49.12 & $<0.001$ \\
\hline GR(SYS) & 0.67 & 0.573 & 0.93 & 0.425 \\
\hline PER(SYS) & 0.17 & 0.680 & 0.32 & 0.571 \\
\hline MON & 1.73 & 0.160 & 2.18 & 0.090 \\
\hline SYS*MON & 5.36 & $<0.001$ & 6.89 & $<0.001$ \\
\hline \multirow[t]{2}{*}{$\mathrm{BW}(\mathrm{MON})$} & 1.08 & 0.366 & 2.48 & 0.043 \\
\hline & \multicolumn{2}{|c|}{ Hyperkeratosis toe/claw } & \multicolumn{2}{|c|}{ Lesions toe/claw } \\
\hline SYS & 9.72 & $<0.001$ & 13.68 & $<0.001$ \\
\hline GR(SYS) & 0.64 & 0.589 & 0.28 & 0.838 \\
\hline PER(SYS) & 0.11 & 0.738 & 0.41 & 0.524 \\
\hline MON & 1.63 & 0.182 & 1.74 & 0.159 \\
\hline SYS*MON & 6.80 & $<0.001$ & 2.16 & 0.046 \\
\hline $\mathrm{BW}(\mathrm{MON})$ & 0.91 & 0.460 & 1.77 & 0.134 \\
\hline
\end{tabular}

SYS = fixed effect of housing system; GR(SYS) = fixed effect of group size within system; PER(SYS) = fixed effect of perch position; $\mathrm{MON}=$ fixed effect of laying month; SYS*MON = interaction between housing system and laying month; BW(MON) = covariate of body weight

Table 3

Distribution of scores for foot pad alterations (\%) within the different housing systems (Verteilung der Grade der Fußballenveränderungen in den verschiedenen Haltungssystemen (\%))

\begin{tabular}{|c|c|c|c|c|c|c|c|c|c|}
\hline Score & AP & $\mathrm{EV}$ & AV & AP & $\mathrm{EV}$ & AV & AP & $\mathrm{EV}$ & AV \\
\hline & \multicolumn{3}{|c|}{ Hyperkeratosis sole pad } & \multicolumn{3}{|c|}{ Hyperkeratosis toe pad } & \multicolumn{3}{|c|}{ Hyperkeratosis toe/claw } \\
\hline 1 & 21.5 & 7.6 & 8.3 & 9.0 & 6.3 & 4.2 & 5.6 & 6.9 & 4.9 \\
\hline 2 & 73.6 & 81.9 & 87.5 & 77.1 & 91.0 & 95.1 & 59.7 & 88.9 & 94.4 \\
\hline 3 & 4.9 & 9.0 & 4.2 & 13.2 & 2.1 & 0.7 & 23.6 & 4.2 & 0.7 \\
\hline 4 & - & 1.4 & - & 0.7 & 0.7 & - & 6.9 & - & - \\
\hline 5 & - & - & - & - & - & - & 4.2 & - & - \\
\hline \multicolumn{4}{|c|}{ Lesion sole pad } & \multicolumn{3}{|c|}{ Lesion toe pad } & \multicolumn{3}{|c|}{ Lesion toe/claw } \\
\hline 1 & 72.9 & 65.3 & 81.3 & 22.2 & 34.0 & 75.0 & 49.7 & 77.8 & 92.4 \\
\hline 2 & 20.1 & 26.4 & 9.7 & 70.1 & 60.4 & 22.2 & 46.2 & 21.5 & 6.3 \\
\hline 3 & 6.3 & 6.9 & 7.6 & 7.6 & 5.6 & 2.1 & 4.2 & 0.7 & 0.7 \\
\hline 4 & 0.7 & 1.4 & 1.4 & - & - & 0.7 & - & - & 0.7 \\
\hline
\end{tabular}

Table 4 shows the least square means with their standard errors and their error probabilities for differences among housing systems on foot pad scores. Laying hens kept in AP showed a significantly lower score for sole pad hyperkeratosis compared to layers from EV and AV. Lesion scores of the toe pad were assessed lowest in AV and highest in AP. The differences between housing systems were significant. Laying hens in AP were significantly higher scored for hyperkeratosis and lesions of the region between toe and claw in comparison to hens from EV. Lesion score of the region between toe and claw was even significantly lower in hens kept in AV than in hens 
housed in AP (Tab. 4). The different perch positions in EV ("stepped", "back perch elevated”) showed no significant influence on foot pad health (Tab. 5).

Table 4

Least square means with their standard errors for foot pad scores of sole, toe and the region between toe and claw for the three different housing systems and their error probabilities (P) for differences among housing systems (LS-Mittelwerte (LSM) der Beurteilungsnoten für Sohle, Zehe und den Übergangsbereich Zehenballen/ Krallensohle einschließlich deren Standardfehler für die drei verschiedenen Haltungssysteme und Irrtumswahrscheinlichkeiten (P) für die Differenzen der LSM zwischen den Haltungssystemen)

\begin{tabular}{lllllll}
\hline & & & & & & \\
Trait & AP (I) & EV (II) & AV (III) & I-II & I-III & II-III \\
\hline Hyperkeratosis sole pad & $1.83 \pm 0.04$ & $2.04 \pm 0.04$ & $1.96 \pm 0.04$ & $<0.001$ & 0.017 & 0.089 \\
Lesion sole pad & $1.34 \pm 0.06$ & $1.43 \pm 0.06$ & $1.29 \pm 0.05$ & 0.261 & 0.575 & 0.098 \\
Hyperkeratosis toe pad & $2.06 \pm 0.03$ & $1.98 \pm 0.04$ & $1.97 \pm 0.09$ & 0.087 & 0.294 & 0.903 \\
Lesion toe pad & $1.87 \pm 0.04$ & $1.72 \pm 0.04$ & $1.29 \pm 0.04$ & 0.012 & $<0.001<0.001$ \\
Hyperkeratosis toe/claw & $2.45 \pm 0.07$ & $1.97 \pm 0.08$ & $1.96 \pm 0.27$ & $<0.001$ & 0.078 & 0.963 \\
Lesion toe/claw & $1.56 \pm 0.05$ & $1.23 \pm 0.05$ & $1.10 \pm 0.12$ & $<0.001$ & 0.001 & 0.351 \\
\hline AP = Aviplus; EV = Eurovent 625a-EU; AV = Aviary & & & & & &
\end{tabular}

Table 5

Least square means with their standard errors for the foot pad scores of sole, toe and the region between toe and claw of layers in Eurovent 625a-EU with different perch positions and their error probabilities (P) for differences among different perch positions (LS-Mittelwerte (LSM) und deren Standardfehler der Beurteilungsnoten für Sohle, Zehe und den Übergangsbereich Zehenballen/ Krallensohle der Legehennen im System Eurovent 625aEU mit verschiedenen Sitzstangenpositionen und Irrtumswahrscheinlichkeiten (P) für die Differenzen der LSM zwischen den Sitzstangenpositionen)

\begin{tabular}{llll}
\hline Trait & \multicolumn{2}{l}{ back perch elevated } & \multicolumn{2}{l}{ 'stepped' perches } \\
(I) & $\begin{array}{l}\text { P } \\
\text { (II) }\end{array}$ & I II \\
\hline Hyperkeratosis sole pad & $2.00 \pm 0.05$ & $2.09 \pm 0.05$ & 0.231 \\
Lesion sole pad & $1.37 \pm 0.08$ & $1.48 \pm 0.08$ & 0.314 \\
Hyperkeratosis toe pad & $1.99 \pm 0.05$ & $1.96 \pm 0.05$ & 0.680 \\
Lesion toe pad & $1.74 \pm 0.06$ & $1.69 \pm 0.06$ & 0.571 \\
Hyperkeratosis between toe/claw & $2.00 \pm 0.12$ & $1.95 \pm 0.12$ & 0.738 \\
Lesion between toe/claw & $1.20 \pm 0.07$ & $1.26 \pm 0.07$ & 0.524 \\
\hline
\end{tabular}

The different scores of foot pad health were positively correlated. Scores for hyperkeratosis in sole pads, toe pads and the region between toe and claw were significantly and positively correlated to scores of lesions in the same regions.

Total plumage condition was significantly influenced by laying month. In the course of the laying period a significant aggravation of total plumage condition was observed in all three housing systems. Housing system tended to be significant on total plumage condition. Laying month had a significant influence on feathering condition of the body regions head, neck, breast and wings (Tab. 6).

Laying hens from AP showed a significantly better total plumage condition compared to layers kept in EV. These significant differences were caused by a more severe deformation of the plumage of hens in EV in the last 4-5 laying months as shown by the least square means by laying month and housing system. Significant differences between EV and the other two housing systems were only found for scores in the 12th laying month (Tab. 7). 
Table 6

Analyses of variance for total plumage condition and plumage condition of the different body regions (Varianzanalyse für den Gesamtgefiederstatus und den Gefiederstatus der verschiedenen Körperregionen)

\begin{tabular}{|c|c|c|c|c|}
\hline \multirow{2}{*}{$\begin{array}{l}\text { Effect } \\
\text { Trait }\end{array}$} & F-value & $\mathrm{P}$ & F-value & $\mathrm{P}$ \\
\hline & \multicolumn{2}{|c|}{ total plumage condition } & head & \\
\hline SYS & 2.92 & 0.055 & 3.96 & 0.020 \\
\hline GR(SYS) & 1.64 & 0.181 & 1.03 & 0.380 \\
\hline PER(SYS) & 0.21 & 0.648 & 0.43 & 0.510 \\
\hline MON & 4.03 & 0.008 & 3.57 & 0.014 \\
\hline SYS*MON & 0.95 & 0.112 & 4.36 & $<0.001$ \\
\hline \multirow[t]{2}{*}{$\mathrm{BW}(\mathrm{MON})$} & 1.74 & 0.433 & 2.97 & 0.020 \\
\hline & neck & & breast & \\
\hline SYS & 18.20 & $<0.001$ & 7.77 & $<0.001$ \\
\hline GR(SYS) & 1.19 & 0.315 & 3.14 & 0.025 \\
\hline PER(SYS) & 0.53 & 0.466 & 0.15 & 0.703 \\
\hline MON & 3.52 & 0.015 & 2.75 & 0.054 \\
\hline SYS*MON & 4.92 & $<0.001$ & 1.71 & 0.117 \\
\hline \multirow[t]{2}{*}{$\mathrm{BW}(\mathrm{MON})$} & 2.37 & 0.052 & 1.18 & 0.320 \\
\hline & belly & & back & \\
\hline SYS & 5.37 & 0.004 & 7.70 & $<0.001$ \\
\hline GR(SYS) & 0.65 & 0.585 & 1.16 & 0.325 \\
\hline PER(SYS) & 0.26 & 0.607 & 1.91 & 0.168 \\
\hline MON & 0.51 & 0.677 & 1.71 & 0.165 \\
\hline SYS*MON & 7.91 & $<0.001$ & 2.91 & 0.009 \\
\hline \multirow[t]{2}{*}{$\mathrm{BW}(\mathrm{MON})$} & 0.52 & 0.722 & 1.11 & 0.353 \\
\hline & wings & & tail & \\
\hline SYS & 14.72 & $<0.001$ & 1.81 & 0.166 \\
\hline GR(SYS) & 3.06 & 0.028 & 2.67 & 0.047 \\
\hline PER(SYS) & 0.00 & 0.954 & 0.09 & 0.765 \\
\hline MON & 3.10 & 0.027 & 0.49 & 0.692 \\
\hline SYS*MON & 0.97 & 0.445 & 1.42 & 0.206 \\
\hline BW(MON) & 1.19 & 0.314 & 0.87 & 0.481 \\
\hline
\end{tabular}

SYS = fixed effect of housing system; GR(SYS) = fixed effect of group size within system; PER(SYS) = fixed effect of perch position; $\mathrm{MON}$ = fixed effect of laying month; SYS*MON = interaction between housing system and laying month; BW(MON) = covariate of body weight

Table 7

Least square means with their standard errors for the total plumage condition in the course of the laying period and their error probabilities (P) for the differences among the different housing systems (LS-Mittelwerte (LSM) und deren Standardfehler für den Gesamtgefiederstatus im Verlauf der Legeperiode und Irrtumswahrscheinlichkeiten (P) für die Differenzen der LSM zwischen den Haltungssystemen)

\begin{tabular}{lllllll}
\hline & AP (I) & EV (II) & AV (III) & \multicolumn{3}{l}{ P } \\
\cline { 5 - 7 } & & & & I-II & I-III & II-III \\
\hline $\begin{array}{l}\text { Average plumage } \\
\text { condition }\end{array}$ & $24.67 \pm 0.20$ & $24.00 \pm 0.23$ & $25.01 \pm 0.62$ & 0.029 & 0.592 & 0.125 \\
LM 3 & $27.48 \pm 0.36$ & $27.34 \pm 0.41$ & $27.64 \pm 0.66$ & 0.784 & 0.831 & 0.698 \\
LM 6 & $25.46 \pm 0.34$ & $25.17 \pm 0.38$ & $26.05 \pm 0.66$ & 0.581 & 0.432 & 0.258 \\
LM 9 & $23.53 \pm 0.35$ & $22.99 \pm 0.38$ & $24.35 \pm 0.66$ & 0.300 & 0.274 & 0.077 \\
LM 12 & $22.21 \pm 0.35$ & $20.51 \pm 0.35$ & $22.03 \pm 0.66$ & $<0.001$ & 0.815 & 0.044 \\
\hline
\end{tabular}

$\mathrm{AP}=$ Aviplus; EV = Eurovent 625a-EU; AV = Aviary ; LM = laying month

Different perch levels in EV showed no influence on total plumage condition, but a significant difference was found for group size in the small aviary system. Layers kept in a group of 40 hens showed a better plumage than layers housed in a compartment with 60 birds. Within the whole laying period, significant differences for the body regions, except the tail, were observed between the three housing systems (Tab. 8). 
Table 8

Least square means with their standard errors for the plumage scoring of the body regions for the different housing systems and their error probabilities (P) for the differences among housing systems (LS-Mittelwerte (LSM) einschließlich deren Standardfehler für den Gefiederstatus der Körperrgionen und Irrtumswahrscheinlichkeiten (P) für die Differenzen der LSM zwischen den Haltungssystemen)

\begin{tabular}{|c|c|c|c|c|c|c|}
\hline \multirow[t]{2}{*}{ Trait } & \multirow[t]{2}{*}{ AP (I) } & \multirow[t]{2}{*}{ EV (II) } & \multirow[t]{2}{*}{ AV (III) } & \multicolumn{3}{|l|}{$\mathrm{P}$} \\
\hline & & & & I-II & I-III & II-III \\
\hline Head & $3.96 \pm 0.02$ & $3.92 \pm 0.02$ & $4.00 \pm 0.02$ & 0.195 & 0.119 & 0.005 \\
\hline Neck & $3.34 \pm 0.04$ & $3.56 \pm 0.04$ & $3.69 \pm 0.04$ & $<0.001$ & $<0.001$ & 0.033 \\
\hline Breast & $3.47 \pm 0.04$ & $3.41 \pm 0.05$ & $3.68 \pm 0.05$ & 0.283 & 0.003 & $<0.001$ \\
\hline Belly & $3.42 \pm 0.08$ & $3.01 \pm 0.10$ & $3.23 \pm 0.27$ & $<0.001$ & 0.473 & 0.440 \\
\hline Back & $3.89 \pm 0.05$ & $3.63 \pm 0.05$ & $3.71 \pm 0.11$ & $<0.001$ & 0.129 & 0.506 \\
\hline Wings & $3.23 \pm 0.04$ & $3.23 \pm 0.04$ & $3.50 \pm 0.04$ & 0.936 & $<0.001$ & $<0.001$ \\
\hline Tail & $3.35 \pm 0.05$ & $3.24 \pm 0.05$ & $3.22 \pm 0.08$ & 0.091 & 0.178 & 0.848 \\
\hline
\end{tabular}

AP = Aviplus; EV = Eurovent 625a-EU; AV = Aviary

Laying hens in AV were scored higher for head, neck, breast and wing plumage condition compared to EV. Furthermore, plumage status for neck, breast and wings was better in AV than in AP. In AP, plumage was higher scored for the regions belly and back compared to EV, whereas in EV neck feathering was better. The regions head, neck, breast and wings showed an aggravation of feathering condition with increasing age of the hens. An exception was head feathering in AV, where birds had the same score for the whole laying period. Group size had a significant influence on the body regions wings and tail. In AP, compartments with 10 hens showed a significantly better plumage condition in wings than groups of 30 hens. In EV, a smaller group size of 40 animals reflected a significantly better status for tail and wing feathering. Feathering of head and neck was significantly associated with body weight. Within the 12th laying month, lighter layers showed a poorer feathering.

Table 9

Least square means with their standard errors for the occurrence of comp lesions in hens kept in different group sizes and compartments with different perch levels in EV and the error probabilities (P) for their differences (LSMittelwerte (LSM) einschließlich deren Standardfehler für das Merkmal Kammläsionen innerhalb verschiedener Gruppengrößen in EV und Irrtumswahrscheinlichkeiten (P) für deren Differenzen)

\begin{tabular}{|c|c|c|c|c|c|c|}
\hline \multirow{2}{*}{ Trait } & \multirow{2}{*}{ EV 40 (I) } & \multirow{2}{*}{ EV 60 (II) } & $\mathrm{P}$ & \multirow{2}{*}{ back perch elevated } & \multirow{2}{*}{$\begin{array}{l}\text { ‘stepped’ } \\
\text { perches }\end{array}$} & $\mathrm{P}$ \\
\hline & & & I-II & & & I-II \\
\hline $\begin{array}{l}\text { comb } \\
\text { lesions }\end{array}$ & $0.003 \pm 0.02$ & $0.081 \pm 0.02$ & 0.006 & $0.011 \pm 0.02$ & $0.073 \pm 0.02$ & 0.031 \\
\hline
\end{tabular}

EV 40 / $60=40$ / 60 hens per compartment in Eurovent 625a-EU

Integument of comb, wattle, cloaca and legs was rarely affected by lesions. In $2.8 \%$ (2.1\% score $1,0.7 \%$ score 2 ) of laying hens in EV, $2.1 \%$ (1.4\% score $1,0.7 \%$ score 2 ) in $\mathrm{AV}$ and $0.7 \%$ in AP (score 1), lesions of the comb were detected. These were superficial lesions or necroses of the comb top. No lesions of the wattles could be observed. Cloacal region was affected in $2.1 \%$ of the hens kept in EV (score 1) and AP (1.4\% score $1,0.7 \%$ score 2 ) and in $0.7 \%$ (score 2 ) of the layers housed in AV. In EV one laying hen showed a lesion assessed with score 1 on the legs. Lesions of the integument were not influenced by housing system. For comb lesions significant differences could be detected for group size and perch position. Keeping laying hens in groups of 60 animals led to more comb lesions, than housing 40 hens per compartment 
$(\mathrm{EV})$. Hens housed in compartments with stepped perches showed more comb lesions compared to those housed in compartments with the back perch elevated (Tab. 9).

Interaction between laying month and housing system was significant in the 9th laying month. Hens in AP were less affected by lesions of the comb compared to hens in EV. Body weight of the birds had a significant influence on the occurrence of comb lesions. In the 9th and 12th laying month, heavier hens had fewer lesions than lighter hens. Cloacal region was more affected by lesions in birds with a higher weight, especially in the 12th laying month, but a significant difference between the housing systems could not be detected for this trait.

Claw length was significantly influenced by housing system. Shortest claws could be observed in AP. Layers in EV showed significantly longer claws compared to hens housed in AV. Furthermore, claw length was significantly affected by laying month. With age of the birds (from the 6th laying month onwards) claw length increased in all the housing systems. Interaction between laying month and housing system was also significant. In the 6th, 9th and 12th laying month, claws were significantly shorter in AP compared to EV, but were significantly longer compared to AV in the 12th laying month. In the 6th and 9th laying month, hens showed significantly longer claws in EV than hens kept in the AV (Tab. 10). Different perch positions in EV did not influence claw length.

Table 10

Least square means with their standard errors for average claw length and claw length in the course of the laying period and their error probabilities $(\mathrm{P})$ for differences among the different housing systems (LS-Mittelwerte (LSM) einschließlich deren Standardfehler für die Gesamt-Krallenlänge und die Krallenlänge im Verlauf der Legeperiode und Irrtumswahrscheinlichkeiten (P) für die Differenzen der LSM zwischen den Haltungssystemen)

\begin{tabular}{lllllll}
\hline Time of measurement & AP (I) & EV (II) & AV (III) & P & \\
\cline { 4 - 7 } & & & & I-II & I-III & II-III \\
\hline Average claw length & $3.76 \pm 0.03$ & $3.30 \pm 0.04$ & $3.65 \pm 0.03$ & $<0.001$ & 0.020 & $<0.001$ \\
LM 3 & $3.90 \pm 0.07$ & $3.79 \pm 0.08$ & $3.94 \pm 0.07$ & 0.287 & 0.620 & 0.138 \\
LM 6 & $3.97 \pm 0.07$ & $3.45 \pm 0.07$ & $3.98 \pm 0.07$ & $<0.001$ & 0.972 & $<0.001$ \\
LM 9 & $3.80 \pm 0.07$ & $3.10 \pm 0.07$ & $3.66 \pm 0.07$ & $<0.001$ & 0.150 & $<0.001$ \\
LM 12 & $3.37 \pm 0.07$ & $2.84 \pm 0.06$ & $3.00 \pm 0.07$ & $<0.001$ & $<0.001$ & 0.080 \\
\hline
\end{tabular}

AP = Aviplus; EV = Eurovent 625a-EU; AV = Aviary; LM = laying month

\section{Discussion}

The objectives of the present study were to evaluate the influence of small aviaries in comparison to a furnished cage system and an aviary system on foot pad health, plumage condition, lesions of the integument and claw length. Mild hyperkeratosis was the most frequently observed finding in all regions of the feet examined. In contrast to WEITZENBÜRGER et al. (2005) sole pad hyperkeratosis showed a similar distribution of severity scores like toe pad hyperkeratosis. Housing systems AP and EV were both equipped with wire floor, but hyperkeratotic alterations in the region between toe and claw were significantly more frequent and severe in hens housed in AP, while sole pad hyperkeratosis occurred significantly more often in EV. An explanation could be a different use of perches, respectively a variable period of time hens spent on the floor. While standing on wire floor or using perches, the hens' feet are exposed to a higher pressure load which can stimulate the skin to proliferate (SIEGWART et al., 1991; KEUTGEN et al., 1999; WEITZENBÜRGER et al., 2005). 
The more severe sole pad hyperkeratosis detected in EV may be explained by different perch surfaces. Compartments in EV with the back perch elevated were equipped with plastic perches similar to AP, combined with a heightened round metal perch. Hens were also able to use the supply pipe of the dust bath for roosting. Compared to the usual perches, the supply pipe and the metal perch had a rough surface made of galvanised zinc. In compartments with the 'stepped' perch design, all perching possibilities were made of this rough material. Different levels of perches had no significant influence on foot pad alterations, so that the rough surface of the central supply pipe or the metal perches can be seen as a possible reason for the increasing occurrence of sole pad hyperkeratosis in EV. WEITZENBÜRGER et al. (2005) also described a possible relationship between the occurrence of sole pad alterations and the use of a rough supply pipe for perching in a type of Eurovent housing system. Another reason for the development of sole pad alterations in EV could be the round form of the perches and the supply pipe. The use of round perches led in different studies to more severe foot pad alterations than the use of rectangular perches (DUNCAN et al., 1992; GLATZ and BARNETT, 1996). In the present study, hyperkeratosis of the region between toe and claw was significantly more often registered in AP compared to hens kept in EV. While sole pad lesions were not significantly influenced by housing system, hens in AP showed significantly higher scores for toe pad lesions and lesions between toe and claw compared to layers housed in EV. Hens from AV were less affected by such alterations. The occurrence of toe lesions and hyperkeratosis in the region between toe and claw in AP could be caused by a longer time hens spent on the wire floor, respectively a lower frequency of perching. Most of the detected toe pad lesions were superficial and often localised in the folds between the toe pads. This could be seen as a consequence of grasping the wire floor. KEUTGEN et al. (1999) observed hyperkeratotic alterations of the region between toe and claw more often in hens kept in conventional cages.

Hyperkeratotic alterations are associated with an increasing risk of the development of lesions. Hyperkeratotic altered skin can easily be colonised by microorganisms, which can further lead to inflammation (WEITZENBÜRGER et al., 2005). A possible coherence between the incidence of hyperkeratosis and the incidence of epithelial lesions could also be observed in the present study. Analyses of correlation showed positively correlated scores of hyperkeratotic alterations and lesions within the same region of the foot. Shortening devices for the claws could be excluded to induce lesions of toe pads in AP and EV, because both housing systems were equipped with the same devices (grindstone). In the 3rd laying month, toe pad lesions were significantly influenced by body weight. Laying hens with a higher weight were more often and severely affected. No impact of body weight could be detected in the further course of the laying period. WANG et al. (1998) mentioned a possible relationship between increased body weight and an increasing risk of food pad dermatitis caused by the higher pressure of the hens' feet on the perches. An unexpected result was the comparable good foot pad status in layers from the aviary system. In many studies, hens housed in aviaries, free range or on floor are often affected by foot pad dermatitis. As a consequence of damp litter and direct contact to excrements, epidermis of the feet can soften and easily be infiltrated by microorganisms. This can result in local inflammation up to ulceration, known as bumble foot (WANG et al., 1998; KEUTGEN et al., 1999). ELSON and CROXALL (2006) stated that the 
occurrence of bumble foot was usually associated with poor perch design and poor perch hygiene. PAGAZAURTUNDUA and WARRIS (2006) found that broilers which were able to use a free range area were more often affected by foot pad dermatitis than broilers housed completely indoors. Broilers in free range had more severe foot pad dermatitis, explained by the possibility to get injured by sharp objects such as stones. In the present study, severe lesions of the sole pad could only be observed in $1.4 \%$ of the aviary-kept hens. Severe lesions of the toe pad and the region between toe and claw combined with a high graded swelling were rarely detected (both $0.7 \%$ ). A good hygiene status of the litter seemed to be responsible for the positive effects on foot health observed in the aviary system. Compared to the wire floor in AP and EV, the plastic slatted floor in AV offered a larger contact surface to the hens' feet. That could have had another positive effect on foot pad health.

If different housing systems were tested and compared to evaluate laying hen welfare, one of the most often examined parameters is the plumage condition. Infectious diseases, alimentary deficiencies or ectoparasites can be causations of poor plumage in laying hens, but the housing system plays a decisive role. Many authors found an influence of the housing system on plumage condition (ABRAHAMSSON et TAUSON, 1997; APPLEBY et al. 2002; WEITZENBÜRGER et al., 2006), whereas others could not detect an impact of housing system (MOINARD et al., 1998). Acquired feather damages can be caused by the equipment of housing systems. But there can also be an abrasion between flock mates, especially if stocking density is high (DUNCAN et al., 1992; APPLEBY et al., 2002). Feeding components can also have an influence on plumage condition (WAHLSTRÖM et al., 2001). Furthermore, feather pecking is a problem in housing laying hens. In the present study a significant difference of the total plumage condition was found between EV and AP. In AP and AV hens had a better plumage condition than layers kept in EV. Neck plumage was assessed lowest for hens in AP and highest for layers housed in AV. While laying hens in the furnished cage AP had to move their head through the grating to reach the feed trough, feeding troughs in the aviary were reachable without touching any furniture elements. This could have had a positive influence on the feathering status of the neck. Feather pecking can lead to a poor plumage condition as well. Hens kept in the aviary system had access to litter and to a covered outdoor area, which offered them various alternatives to perform foraging and exploring behaviour. MAHBOUB et al. (2004) examined the use of an outdoor area and detected an increasing risk of feather pecking, when hens were less attracted to the grassland area. Hens in EV also showed a significantly lower score for the plumage condition of belly and back in comparison to layers housed in AP. As furniture can lead to an abrasion and aggravation of plumage (DUNCAN et al., 1992; APPLEBY et al. 2002; WEITZENBÜRGER et al., 2006), the elevated perches on different positions in EV could be causal for the more damaged belly and back region and furthermore for the lower total plumage condition. However, the different perch design was not important for plumage condition and perch position was not significant in the analyses of variance. Wing feathering was assessed significantly higher in AV compared to hens in AP and EV. Laying hens in AV were offered more space, thus reducing the risk of touching furniture elements while moving around or flapping with wings. In the present study and in agreement with WEITZENBÜRGER et al. (2006), group size had a significant influence on total plumage condition and furthermore on some of the body regions. Groups of 40 hens 
per compartment had a significantly better total plumage condition than hens housed in groups of 60 birds. Also for the body regions wings and tail, groups stocked with 60 hens in EV were significantly lower scored. Wing feathering status in AP was better in 10 bird compartments compared to compartments with 30 hens. In the course of the laying period an aggravation of the total plumage condition was more evident in EV than in the other housing systems. The general trend of a decreasing plumage condition in all housing systems over the laying period was in agreement with other authors (GLATZ and BARNETT, 1996; BARNETT et al., 1997; WAHLSTRÖM et al., 2001; NICOL et al. 2006; WEITZENBÜRGER et al., 2006).

Injuries of the integument are affected by housing system and are mainly caused by pecking (KEUTGEN et al., 1999). ABRAHAMSSON and TAUSON (1997) observed a lower incidence of rear body wounds in furnished cages compared to conventional cages. In our investigation only a few birds showed lesions of the integument. Status of the integument was not influenced by housing system. Group size had a significant influence on the occurrence of comb lesions. In groups of 60 hens in $\mathrm{EV}$, comb lesions were observed more often. No effects on pecking or cannibalistic behaviour between different group sizes could be detected by ABRAHAMSSON and TAUSON (1997). They found a relationship between larger denuded rear parts and a higher frequency of rear body wounds. In the present study, a significant influence on comb wounds could also be observed for perch position. Birds in compartments with 'stepped' perches were more affected by comb lesions than layers kept in compartments with the back perch elevated.

Abrasion of claws is related to housing system (WEITZENBÜRGER et al., 2006). Various possibilities to shorten claws are offered by different types of shortening devices in furnished cages and small group housing systems, such as grindstones, adhesive stripes or perforated metal plates, but also by different floor surfaces like wire floor or littered areas in alternative housing systems. WEITZENBÜRGER et al. (2006) observed the highest effect of abrasion in furnished cages with two grindstones, the lowest in compartments with perforated metal plates. Despite the same shortening devices (grindstones) for the claws in $\mathrm{AP}$ and $\mathrm{EV}$, claw length was highest in $\mathrm{EV}$ and shortest in AP. In agreement with BARNETT et al. (1997) this effect may be explained with the preference of the hens in EV to spend more time on perches and consequently had less contact to other surfaces. The influence of the presence of perches on claw length is not consistently discussed. Claw length increases with age of laying hens (BARNETT et al., 1997; WAHLSTRÖM et al., 2000; WEITZENBÜRGER et al., 2006). A significant effect of laying month on claw length was also observed in the present study in all three housing systems and the differences among EV and the other two systems increased with the number of laying months, whereas in the 12th laying month claw length increased in AP and AV more rapidly than in EV. A possible reason for increasing claw growth in AP during the last laying months could be an advanced abrasion of the adhesive claw shortening devices. For hens in AV high temperatures in the summer may have reduced the hens' mobility and the exploring behaviour in the winter garden-like outdoor area.

In conclusion, housing laying hens in AP and EV did not lead to proliferative foot pad hyperkeratosis with swelling of foot pads, because most of the findings were assessed as mild alterations. Foot pad status was not influenced by different perch positions, but perch design and perch surface seemed to have an influence on the occurrence of foot 
pad alterations in the small aviary housing system. Positive effects on foot pad health were observed in the aviary. In none of the housing systems overall total plumage condition was critical, because scores were above 24 (at the end of the laying period > 20). Plumage condition was not affected by different perch positions. Injuries of the integument were rarely detected and an obvious claw overgrowth could not be observed.

\section{Acknowledgements}

The authors are grateful to Big Dutchman GmbH, Deutsche Frühstücksei GmbH and Lohmann Tierzucht GmbH for their support of this scientific project.

\section{References}

ABRAHAMSSON, P.; TAUSON, R.: Effect of perches at different positions in conventional cages for laying hens of two different strains. Acta Agric. Scand. 43 (1993), 228-235

ABRAHAMSSON, P.; TAUSON, R.: Effects of group size on performance, health and birds' use of facilities in furnished cages for laying hens. Acta Agric. Scand. 47 (1997), 254-260

APPLEBY, M.C.; WALKER, A.W.; NICOL, C.J.; LINDBERG, A.C.; FREIRE, R.; HUGHES, B.O.; ELSON, H.A.:

Development of furnished cages for laying hens. Br. Poult. Sci. 43 (2002), 489-550

BARNETT, J.L.; GLATZ, P.C.; NEWMAN, E.A.; CRONIN, G.M.:

Effects of modifying layer cages with perches on stress physiology, plumage, pecking and bone strength of hens. Aust. J. Exp. Agric. 37 (1997), 523-529

DUNCAN, E.T.; APPLEBY, M.C.; HUGHES, B.O.: Effects of perches in laying cages on welfare and production of hens. Br. Poult. Sci. 33 (1992), 25-35

ELSON, H.A.; CROXALL, R.: European study on the comparative welfare of laying hens in cage and non-cage systems. Arch. Geflügelk. 70 (2006), 94-198

GLATZ, P.C.; BARNETT, J.L.:

Effects of perches and solid sides on production, plumage and foot condition of laying hens housed in conventional cages in a naturally ventilated shed. Aust. J. Exp. Agric. 36 (1996), 269-275

KEUTGEN, H.; WURM, S.; UEBERSCHÄR, S.: Pathologisch-anatomische Untersuchungen bei Legehennen aus verschiedenen Haltungssystemen. Dtsch. tierärztl. Wschr. 106 (1999), 127-133

MAHBOUB, H.D.H.; MÜLLER, J.; VON BORELL, E.: Outdoor use, tonic immobility, heterophil/ lymphocyte ratio and feather condition in free-range laying hens of different genotype. Br. Poult. Sci. 45 (2004), 738-744

MOINARD, C.; MORISSE, J.P.; FAURE, J.M.: Effect of cage area, cage height and perches on feather condition, bone breakage and mortality of laying hens. Br. Poult. Sci. 39 (1998), 198-202

NICOL, C.J.; BROWN, S.N.; GLEN, E.; POPE, S.J.; SHORT, F.J.; WARRIS, P.D.; ZIMMERMAN, P.H.; WILKINS, L.J.:

Effects of stocking density, flock size and management on the welfare of laying hens in single-tier aviaries. Br. Poult. Sci. 47 (2006), 135-146

PAGAZAURTUNDUA, A.; WARRISS, P.D.:

Levels of foot pad dermatitis in broiler chickens reared in 5 different systems. Br. Poult. Sci. 47 (2006), 529-532

SIEGWART, N.:

Ursache und Pathogenese von Fußballengeschwüren bei Legehennen. Doctoral Thesis, University of Bern (1991)

TAUSON, R.; ABRAHAMSSON, P.:

Foot and skeletal disorders in laying hens. Acta Agric. Scand. 44 (1994), 110-119

WANG, G.; EKSTRAND, C.; SVEDBERG, J.:

Wet litter and perches as risk factors for the development of foot pad dermatitis in floor-housed hens. Br. Poult. Sci. 39 (1998), 191-197

WAHLSTRÖM, A.; TAUSON, R.; ELWINGER, K.: 
Plumage condition and health of aviary-kept hens fed mash or crumbled pellets. Poult. Sci. 80 (2001), 266-271

WEITZENBÜRGER, D.; VITS, A.; HAMANN, H.; HEWICKER-TRAUTWEIN, M.; DISTL, O.:

Evaluierung von Kleingruppenhaltungssystemen und ausgestalteten Käfigen im Hinblick auf den Fußballenstatus bei Legehennen. Berl. Münch. Tierärztl. Wschr. 118 (2005), 270-279

WEITZENBÜRGER, D.; VITS, A.; HAMANN, H.; DISTL, O.:

Evaluierung von Kleingruppenhaltungssystemen und ausgestalteten Käfigen hinsichtlich Brustbeindeformationen, Gefiederstaus, Krallenlänge und Körpermasse bei den Legelinien Lohmann Selected Leghorn und Lohmann Brown. Arch. Tierz., Dummerstorf 46 (2006), 89-102

VITS, A.; WEITZENBÜRGER, D; HAMANN, H.; DISTL, O.:

Production, egg quality, bone strength, claw length, and keel bone deformities of laying hens housed in furnished cages with different group sizes. Poult. Sci. 84 (2005), 1511-1519

Received: 2006-12-27

Accepted: 2007-04-24

Corresponding Author

Prof. Dr. OTTMAR DISTL

Institut für Tierzucht und Vererbungsforschung,

Stiftung Tierärztliche Hochschule Hannover

Bünteweg 17p

30559 HANNOVER, GERMANY

E-Mail: ottmar.distl@tiho-hannover.de 